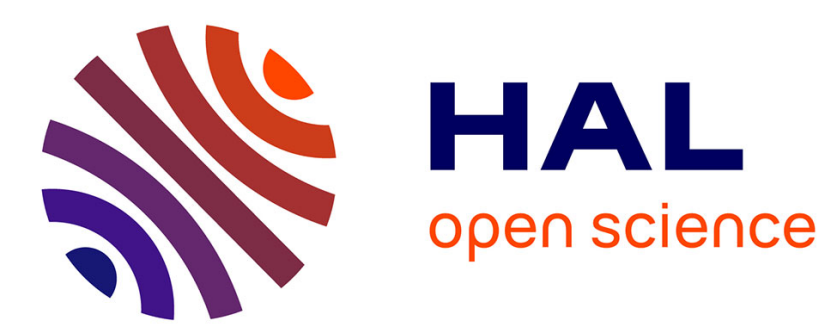

\title{
Active flow control in an axial compressor for stability improvement: on the effect of flow control on stall inception
}

Gabriel Margalida, Pierric Joseph, Olivier Roussette, Antoine Dazin

\section{- To cite this version:}

Gabriel Margalida, Pierric Joseph, Olivier Roussette, Antoine Dazin. Active flow control in an axial compressor for stability improvement: on the effect of flow control on stall inception. Experiments in Fluids, 2021, 62, pp.12. 10.1007/s00348-020-03104-4 . hal-03109223

\section{HAL Id: hal-03109223 \\ https://hal.science/hal-03109223}

Submitted on 27 Jan 2021

HAL is a multi-disciplinary open access archive for the deposit and dissemination of scientific research documents, whether they are published or not. The documents may come from teaching and research institutions in France or abroad, or from public or private research centers.
L'archive ouverte pluridisciplinaire HAL, est destinée au dépôt et à la diffusion de documents scientifiques de niveau recherche, publiés ou non, émanant des établissements d'enseignement et de recherche français ou étrangers, des laboratoires publics ou privés. 


\title{
Active flow control in an axial compressor for sta- bility improvement: On the effect of flow con- trol on stall inception
}

\author{
Gabriel Margalida ${ }^{1}$, Pierric Joseph ${ }^{1}$, Olivier Roussette ${ }^{1}$ and Antoine Dazin ${ }^{1 *}$ \\ ${ }^{1}$ Univ. Lille, CNRS, ONERA, Arts et Metiers Institute of Technology, Centrale Lille, UMR 9014 - \\ LMFL \\ Laboratoire de Mécanique des fluides de Lille - Kampé de Fériet, F-59000 Lille, France. \\ * Correspondence: antoine.dazin@ensam.eu ;
}

\begin{abstract}
In this paper, the effect of an active flow control system on the onset mechanisms of rotating stall in an axial compressor is experimentally investigated. A particular emphasis is thus given on the flow patterns present in the tip region right before stall and how they evolve when active flow control is applied. The mechanisms involved during stall formation without control are carefully assessed and compared to the literature. To this purpose, the development of the first instability into rotating stall is discussed by monitoring its speed inside the compressor. This analysis also relies on instantaneous pressure measurements at the casing of the compressor.
\end{abstract}




\section{INTRODUCTION}

One of the major issues that penalize modern aircraft engines, lies in the loss of stability when the compressor pressure ratio is increased.

To respond to the urgent need to reduce engines emissions, one solution is to increase the operating range of the compressors and to operate them at higher pressure ratios. To do so, delaying the rotating stall onset becomes more and more critical, especially with the future generation of engines which aims at smaller core and Boundary Layer Ingestion (BLI) where this issue is even more limiting.

To tackle this problem, lot of efforts have been invested into designing and implementing effective passive or active flow control systems to delay the onset of the stall phenomenon without affecting the performances at nominal conditions. In parallel to these works, the understanding of the inception of the first instability has been refined. Several routes to stall have been observed (Camp and Day 1997), with the now well known "mode" (McDougall et al. 1990) and "spike" (Day 1993) type rotating stall, and detailed flow mechanisms for each process have been proposed thanks to a combination of experimental and numerical works.

While the definition of the "mode" type rotating stall inception is very clear in the literature, "spike" type rotating stall, and more importantly the "spike" itself, can correspond to different physical phenomena. In some cases, this denomination can thus be misleading, and a more precise analysis of the stall inception mechanisms is often necessary.

Historically, "spike" is the name given to the short-scale perturbation spotted in the velocity or pressure signals directly prior to the rotating stall, few revolutions earlier, and rotating at $\sim 70 \%$ of the rotor rotation speed. A strong correlation has firstly been observed between the spike onset and the upstream displacement of the interface between the Tip Leakage Flow (TLF) and the incoming flow (Hoying et al. 1999). As the operating point moves closer to the stability limit, the mass flow decreases and thus the incoming flow weakens in respect to the TLF which then push the interface. More recently, experimental (Deppe et al. 2005) and numerical works (Vo et al. 2008) have showed that the "spike" is directly linked to the tip leakage flow, and a criterion involving two simultaneous conditions has been proposed (Vo et al. 2008) (see Fig. 1).

The first condition specifies that the interface between the tip leakage flow and the main flow should be parallel to the leading-edge plane. This condition leads to the disturbance of the leadingedge region by the Tip Leakage Vortex (TLV) and paves the way to the second condition. This second one relies on a simultaneous spillage of the tip leakage in front of the leading edge of a blade and a backflow at the trailing edge of the previous one. This backflow will then reinforce the spillage. However, recent studies have brought new elements on the table. Pullan et al. (2015) have observed typical pressure spikes on the pressure signals extracted from numerical simulations undergone on configurations without any tip gap, and thus without tip leakage nor backward spillage. Moreover, they spotted the formation of radial vortices, extending from the suction side of blades to the casing, and they linked these structures to the "spike" they observed. These radial vortices had been already observed, in fact, by Inoue et al. (Inoue et al. 2001, 2004) and Yamada et al. (Yamada et al. 2013), in a large tip gap configuration in parallel to tip leakage vortex breakdown, just prior stall formation. 


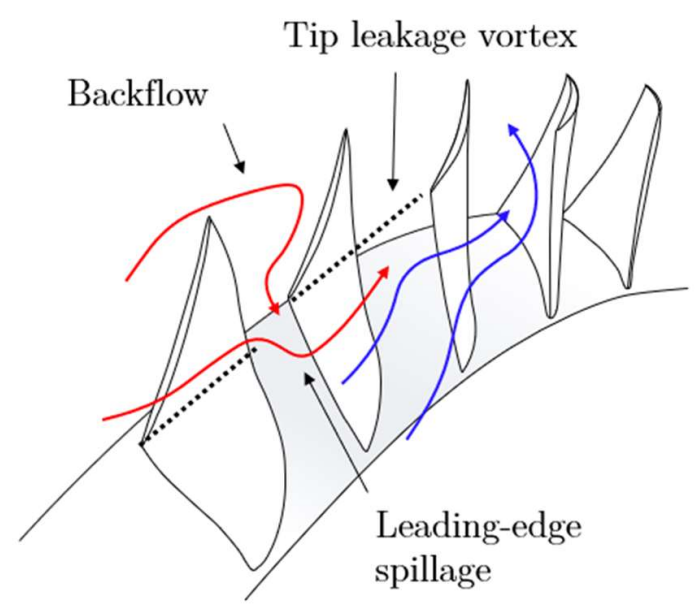

Fig. 1 Schematic representation of the flow conditions required for spike onset, (Vo et al. 2008)

Even more recently, these results have been completed by a numerical analysis of the effect of the tip gap size on the flow mechanism involved during stall inception and a strong link between both has been reported (Hewkin-Smith et al. 2019). It has been especially shown that for small tip clearance (under a critical value of $\tau=0.5 \%$.C), no spillage happens and that the rotating stall is caused by an increase of the incidence due to blockages at the exit of the blade passage. On the contrary, for bigger tip clearance, the leakage momentum prevents the formation of these blockages, but backflows can occur. These two modes of "spike" type rotating stall are respectively referred as "casing corner separation dominated" and "tip leakage jet dominated".

In parallel Active control technics, and more precisely discrete tip injection, have shown their effectiveness on the improvement of the compressor stability by moving away the surge line (Suder et al. 2001; Nie et al. 2002; Kefalakis and Papailiou 2007; Li et al. 2014). Some successful applications have also been demonstrated on real aircraft engines (Stößel et al. 2013, 2014). Understanding their effects is thus of first interest but surprisingly, few works have investigated the mechanisms involved when active flow control is applied and how it affects the flow patterns in the tip gap while extensive work in this domain has been done with casing treatments (Takata and Tsukuda 1977; Smith and Cumpsty 1983; Fujita and Takata 1984; Cumpsty 1989).

The main goal of this paper is to analyze the effect of the active flow control system on a compressor stage: how the flow patterns are affected by the blowing and how it affects the performances of the stage. To do so, the paper will first present the flow mechanisms associated with the stall inception in the compressor, in a base state, without control. For these tasks, well refined unsteady pressure measurements are used to monitor the development of the first instants of the rotating stall and to produce detailed pressure fields. 


\section{EXPERIMENTAL SETUP}

\section{Test compressor and control system}

The experimental study of the effect of the pulsed air injection on stability improvement has been conducted on the single stage low pressure axial compressor CME2 operated at 3200RPM. The main characteristics of the compressor are reminded in Table 1and more details are available in a previous paper (Veglio et al. 2014). A general view of the test rig is given in Fig. 2 and the performance curve is plotted in Fig. 3, where the total-to-static pressure rise coefficient $\Psi_{t-s}=\Delta P_{t-s}$ $/ 0.5 \rho U_{t i p}{ }^{2}$ is represented as a function of the flow coefficient $\Phi=V_{x} / U_{\text {mid }}$. More information about the compressor can be found in a previous paper (Margalida et al. 2018).

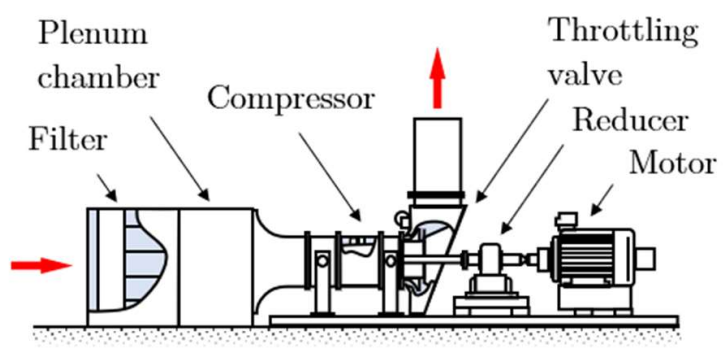

Fig. 2 CME2 axial compressor

\begin{tabular}{lrl}
\hline Rotational speed & 3200 & $\mathrm{rpm}$ \\
Design mass flow rate & 5.3 & $\mathrm{~kg} . \mathrm{s}^{-1}$ \\
Design axial velocity, LE & 43 & $\mathrm{~m} . \mathrm{s}^{-1}$ \\
Rotor blade number & \multicolumn{2}{c}{30} \\
Stator blade number & \multicolumn{2}{c}{40} \\
Casing diameter & $550 \mathrm{~mm}$ \\
Hub-tip ratio, LE & 0.75 \\
Rotor tip chord & $84 \mathrm{~mm}$ \\
Rotor tip stagger angle & 54 & $\circ$ \\
Rotor tip gap & $0.5 \mathrm{~mm}$ \\
\hline
\end{tabular}

Table 1 Compressor parameters

The air injection system is composed of 20 injection blocks divided into two injectors (this configuration of 20 blocks of two injectors has been preferred to 20 bigger injectors mainly because of the space constraints and to limit their protrusion on the inner surface of the casing). Each injector has its own solenoid valve (Matrix, model MX821) whose frequency ranges from 0 to $500 \mathrm{~Hz}$ with an inlet pressure between 0 and 8 bar relative generating jet speed up to $200 \mathrm{~m} \cdot \mathrm{s}^{-1}$. Each injection block can be operated independently from the others and they are all linked to the same compressed air supply through 10 distributors equally spaced around the compressor. 


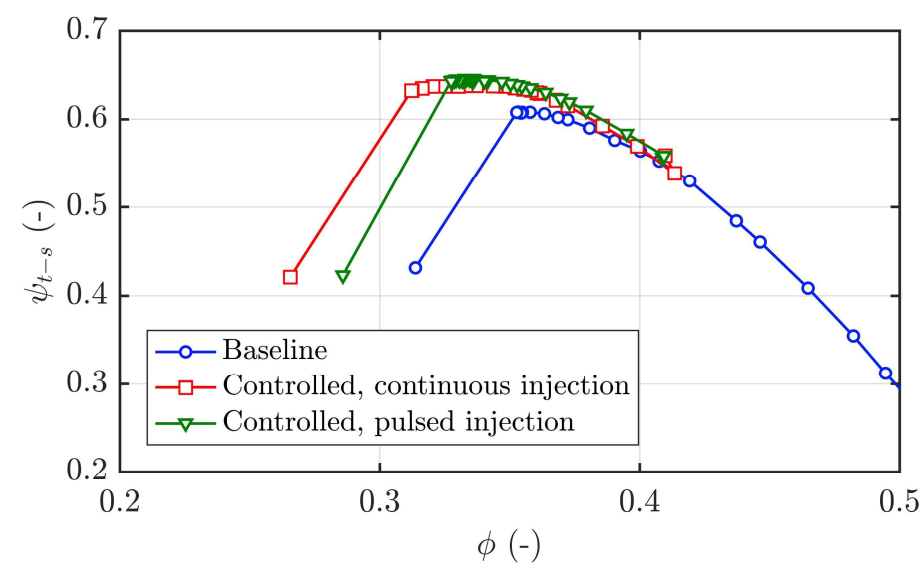

Fig. 3 Compressor performances without and with active flow control (continuous injection, 30 injectors, $q_{i}=1.7 \% . q$, $v_{i}=137 \mathrm{~m} . \mathrm{s}^{-1}$; pulsed injection, 20 injectors, $q_{i}=0.7 \% . q, v_{i}=108 \mathrm{~m} \cdot \mathrm{s}^{-1}$ )

To benefit as much as possible of the injection at the tip leading edge (the performances of the injection increases when the jet is closer to this region (Nie et al. 2002)) the injectors are located $10 \mathrm{~mm}$ upstream of the leading edge of the rotor $\left(x=-20 \% \cdot \mathrm{C}_{\mathrm{x}}\right)$ and they have been designed to take profit of Coandă effect, already used by Strazisar et al. (2004), allowing a tangential blowing, attached to the casing. The injected mass flow rate can be changed from $0 \%$ to $2 \%$ of the compressor mass flow rate either by changing the supply pressure or the duty cycle of the solenoid valves when pulsed injection is used. For this study, the injectors blow axially through $10 \mathrm{~mm}$ wide slots. The control system is presented on Fig. 4.

\section{Measurement setup and experimental procedure}

To evaluate the performances of the compressor, three static pressures $\left(\mathrm{P}_{\mathrm{s} 02}, \mathrm{P}_{\mathrm{s} 10}, \mathrm{P}_{\mathrm{s} 20}\right)$ and one total pressure $\left(\mathrm{P}_{\mathrm{t} 01}\right)$ are measured at different axial locations of the test bench. Their location is displayed on Fig. 5.(a). In controlled operation, the total pressure at inlet is corrected by the added kinetic pressure coming from the jets, which was determined by hot-wire measurements. The mass flow rate and static-to-static pressure rise measurement uncertainties are respectively equal to $\pm 0.012 \mathrm{~kg} . \mathrm{s}^{-1}$ and $\pm 1.3 \mathrm{~Pa}$.

The instantaneous pressure measurements were realized with unsteady pressure transducers (Endevco model 8507C-1 and 8510B-1), flush mounted on the casing. To monitor the development of the rotating stall, 20 sensors distributed all around the compressor just upstream the leading edge of the rotor $\left(x / C_{x}=-0.06\right)$, as represented on Fig. 5.(b), have been simultaneously used. The pressure contours of the tip leakage flow are obtained through 14 pressure probes aligned axially every $4 \mathrm{~mm}$, at the same angular position, from the leading edge $\left(x / C_{x}=-0.04\right)$ to the trailing edge $\left(x / C_{x}\right.$ $=+1$ ) (see Fig. 5.(c)).

The sampling rate for each test was set to $100 \mathrm{kHz}$, corresponding to more than 60 measurement points on each blade channel at 3200RPM, allowing to catch perturbations of small temporal and spatial extent. The pressure transducers uncertainty ranges from $0.5 \%$ to $1.5 \%$ of the full-scale output. 


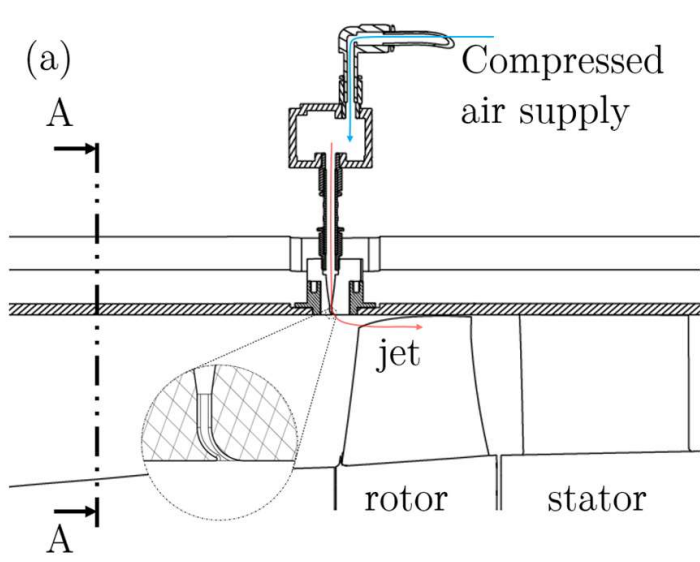

Injection bloc

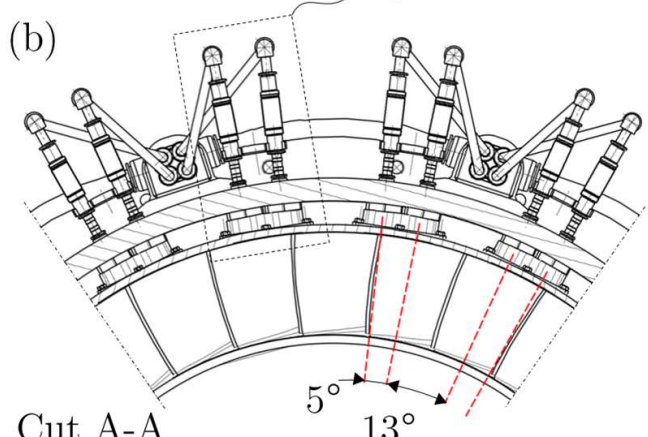

(c)

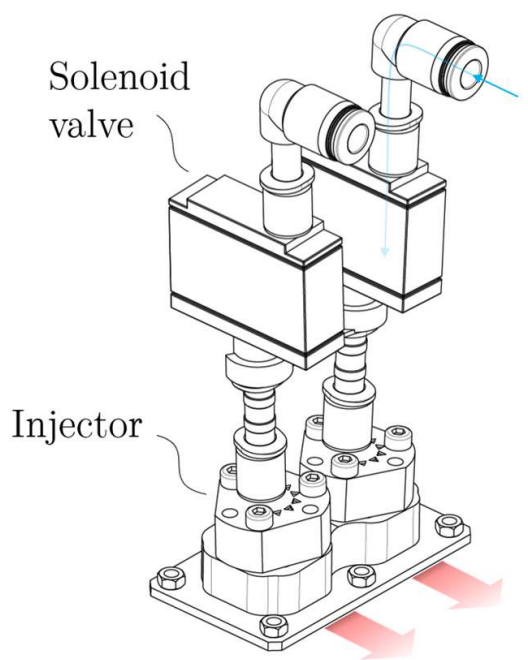

(d)

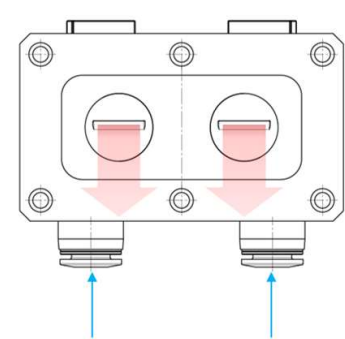

Fig. 4 Drawings of the control system. Axial (a) and radial (b) cutaway of the control system implemented on the compressor, isometric view of one injection bloc (c) and bottom view (d).
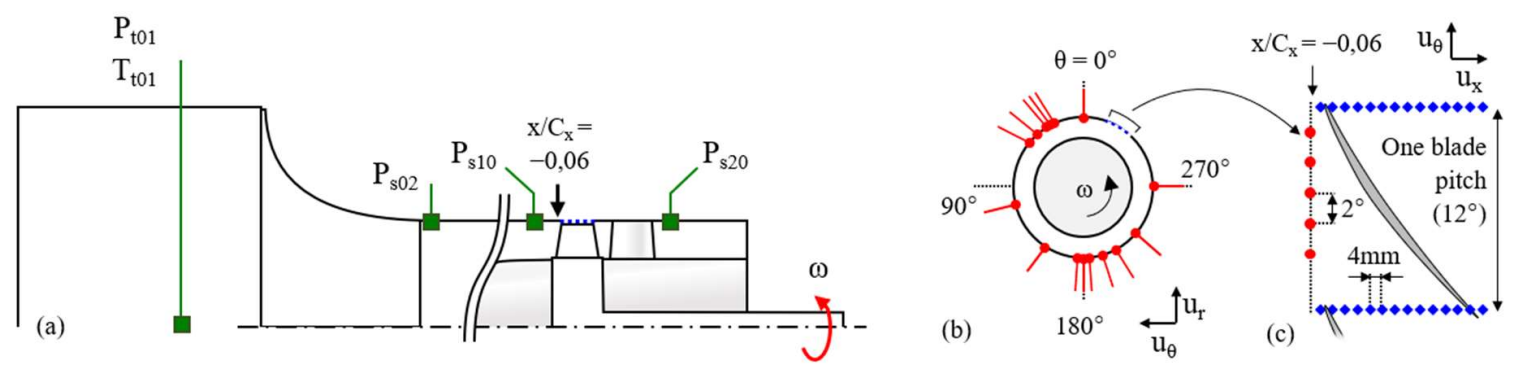

Fig. 5 Measurement setup

To trigger the rotating stall, the mass flow rate is slowly decreased using the throttling valve visible on Fig. 2. For all instantaneous measurements (i.e. pressure fields and perturbation monitoring), the throttling process is continuous and similar to the procedure described in a previous paper(Margalida et al. 2020). For performance measurements however, the process is realized point by point, interspersed with stabilization phase, by carefully decreasing the mass flow from one operating point to the next one. For the last stability point (last point of the performance curve before stall), it is worth mentioning that the stall onset is spontaneous. 


\section{RESULTS AND DISCUSSION}

\section{Stall onset in the axial compressor CME2}

Before looking at the effect of the air injection on the flow pattern at stall onset, it is necessary to clearly determine the mechanism involved without control. The first thing that can be noticed is the slope of the total-to-static performance curve at the last stability point. When the stability limit is reached before the maximum of the performance curve, the compressor is most likely to exhibit "spike" type rotating stall (Camp and Day 1997). A look at the filtered instantaneous pressure traces (Butterworth, $3^{\text {rd }}$ order, $250 \mathrm{~Hz}$ ), represented on Fig. 6, confirms this first observation. Indeed, no modal activities can be spotted long before rotating stall while a sudden pressure spike is visible at the beginning of the phenomenon. The absence of modal perturbations has also been confirmed through spectral analysis.

In the literature, tip leakage spillage and spike type rotating stall has been observed experimentally on compressors with relatively large tip clearances, between $\tau=1 \%$ to $\tau=2 \%$ (see Table 2), compared to the critical value exhibited by Hewkin-Smith et al. (2019). The axial compressor CME2 however, features a tip clearance of $\tau=0.6 \%$, making it more representative of the configuration used by Pullan et al. (2015) and Hewkin-Smith et al. (2019) for small tip clearances.

\begin{tabular}{ll}
\hline Compressor used & $\tau=\mathrm{s} / \mathrm{C}$ \\
\hline $\begin{array}{l}\text { Pfleiderer-Inst. stage 2, (Deppe et } \\
\text { al. 2005) }\end{array}$ & 0.015 \\
$\begin{array}{l}\text { Deverson compressor, (Day 1993; } \\
\text { Weichert and Day 2013) }\end{array}$ & 0.012 \\
$\mathrm{E}^{3}$ Rotor B, (Vo et al. 2008; Pullan & 0 \\
et al. 2015; Hewkin-Smith et al. & 0.018 \\
2019) & \\
CME2 & 0.006 \\
\hline
\end{tabular}

Table 2 Normalized tip clearance size, $\tau=s / C$, for different compressors

To determine the mechanism involved at stall onset, flow features at the scale of the blade passage are investigated in order to check for the clues of tip leakage spillage, associated to the "spike", observed by other authors. One of them is associated to the backflow at the exit of a blade passage where the first spike occurs. We can see on Fig. 6.(a) that no overpressure is visible, unlike Deppe et al. (2005) measurements, shown on Fig. 6.(b), where tip leakage spillage has been observed. Both experimental setups are operated at an equivalent rotational speed and exhibit relatively close nominal conditions, but they have very different tip clearance sizes relative to their chord length. The observation is also true when comparing with other compressors where spillage has been observed. 

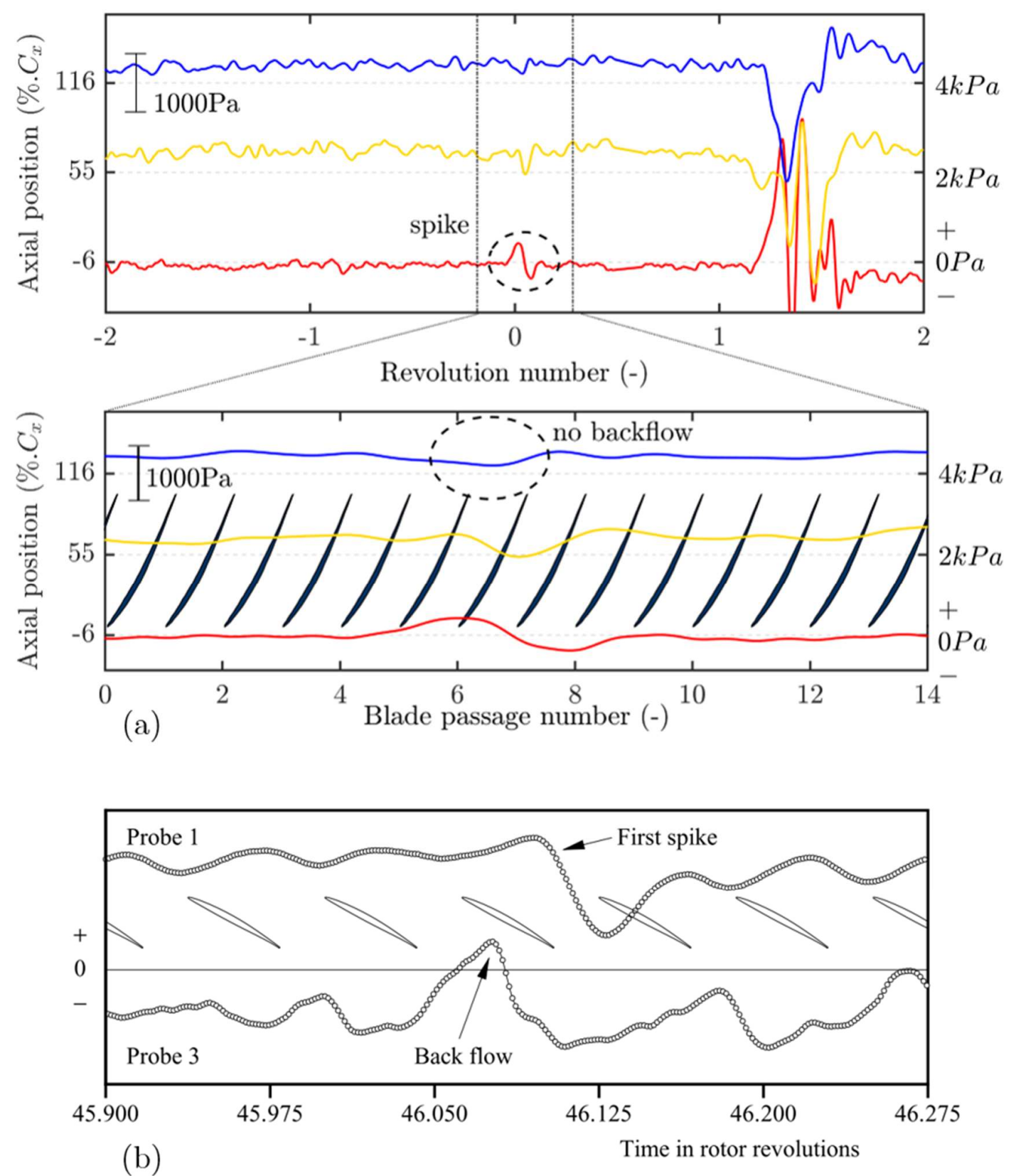

Fig. 6 Filtered instantaneous pressure trace for three axial locations in the CME2 compressor (a) and from the literature exhibiting backflows (Deppe et al. 2005) (b)

On Fig. 7, two instantaneous pressure contours of the first half of the passage and distant of one blade pitch, are displayed near stall. Each blade passage will be referred by the number of the blades surrounding it and the same reference is kept from one plot to the other. On these plots, one can easily notice the presence of numerous low pressure spots that can be the signature of radial vortices (noted from "A" to "F"), equivalent to the ones highlighted by Pullan et al. (2015). It is also possible to see that those spots have a very short lifespan, of the order of one blade pitch. 
Indeed, spot "C" and "D" or " $A$ " and "E" are not visible respectively one blade pitch later and one blade pitch earlier on Fig. 7.(a) and Fig. 7.(b). On the contrary spots "B" and "F", firstly seen on Fig. 7.(b) close to the suction side of blade 2 and 6, are closer to the leading edge of blade 3 and 7 on Fig. 7.(a) ${ }^{1}$. These radial vortices, also called tornado like vortex in the literature, are often associated to rotating instabilities such as in the work of Young et al. (2012). However, the disturbances observed here differ from them on some points. Rotating instabilities, which evolve in compressor with larger tip clearance, tend to have longer, but irregular, lifespan (several revolutions, (Young et al. 2012; Yamada et al. 2013)). This characteristic, coupled with their unsteady nature, leads to the presence of a "hump" (Young et al. 2012), visible on the frequency spectrum, at a fraction of the blade passing frequency. As explained earlier, the perturbations observed here have a shorter lifespan which explain the absence of the typical "hump" associated to rotating instabilities. These disturbances appear downstream the leading edge of the rotor and they are quickly convected from the suction side of one blade to the pressure side of the following one.

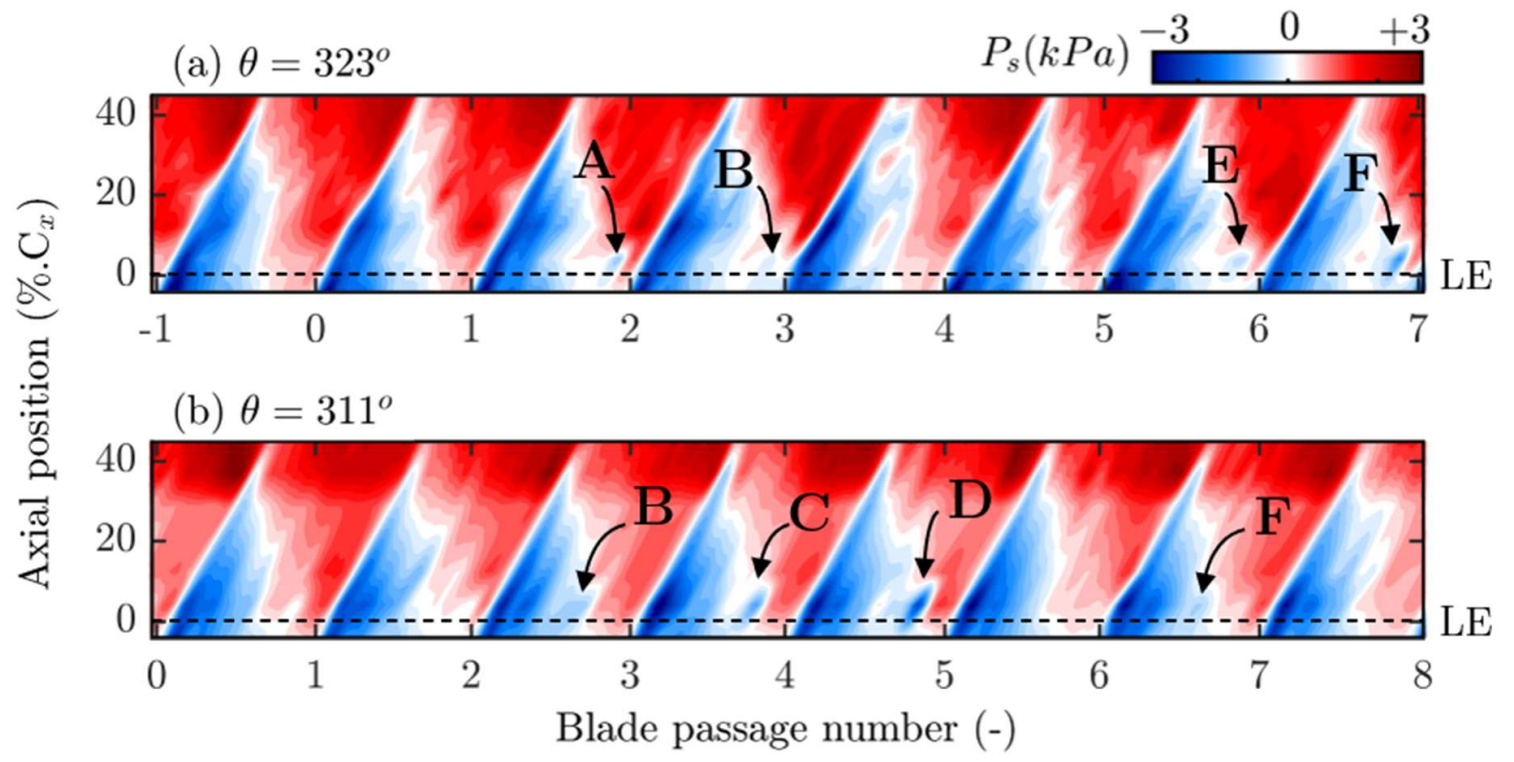

Fig. 7 Pressure contour at two angular positions, one blade pitch apart, near stall

On Fig. 8 three pressure contours are represented for three operating points, near nominal conditions, marked $t_{0}$, and two at stall onset, 1.5 revolutions apart, marked $t_{1}$ and $t_{2}$. A filtered pressure trace at the beginning of the rotating stall is also presented on Fig. 8.(d) for reference. On Fig. 8.(c), a blocked channel between blade 3 and 4, noted "B" (greater static pressure at the inlet and pressure drop " $\mathrm{D}$ " at the exit, circumference wise, and zero pressure gradient blade to blade and leading edge to trailing edge) and a large low-pressure region between blade 4 and 5, noted "C", can be seen. When the filtered pressure trace is observed at the leading edge, one can see that the perturbation is characterized by a rapid pressure oscillation, of the same kind of typical "spike". However,

\footnotetext{
${ }^{1}$ It is hard, though, to assert with total certainty that spot "B" and "F" of Fig. 7.(a) are the same than their counterparts of Fig. 7.(b) and not new ones. However, even if the second case apply, the conclusion of the short lifespan of the perturbation remains valid.
} 
1.5 revolutions earlier, on Fig. 8.(b), it can be seen that the channel 2-3 exhibits a pressure drop, referred "A", from one blade to the other. This event is well highlighted by an iso-pressure line at the rotor inlet, represented by the black line, which connects the suction side of blade 4 to the leading edge of blade 5. Finally, it is possible to see that the well-defined TLV on Fig. 8.(a) disappears close to the stability limit, on pressure contour (b) and (c), suggesting a highly unsteady TLV (this feature had already been seen in past works, on phase averaged pressure maps with the TLV trace splitting in two close to the stability limit, see (Veglio et al. 2014)).
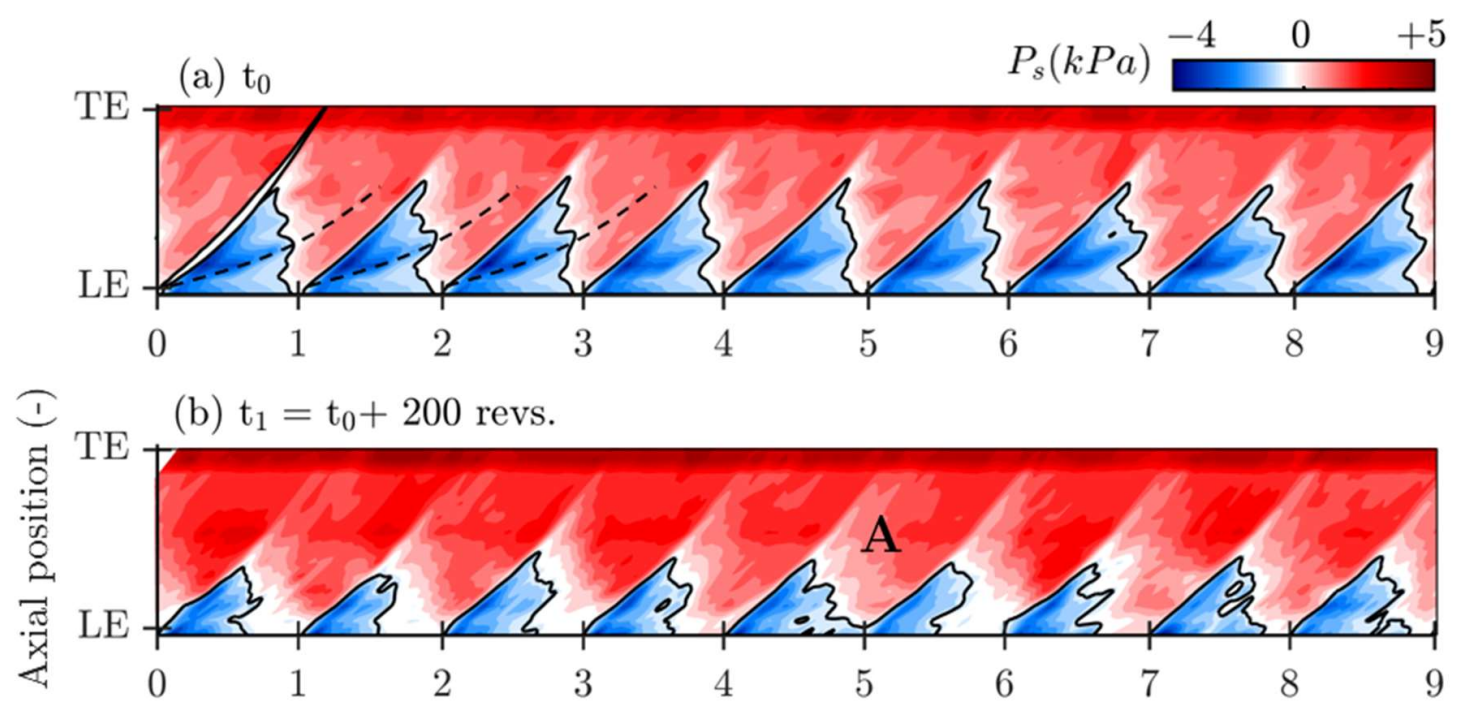

(c) $\mathrm{t}_{2}=\mathrm{t}_{1}+1.5$ revs.

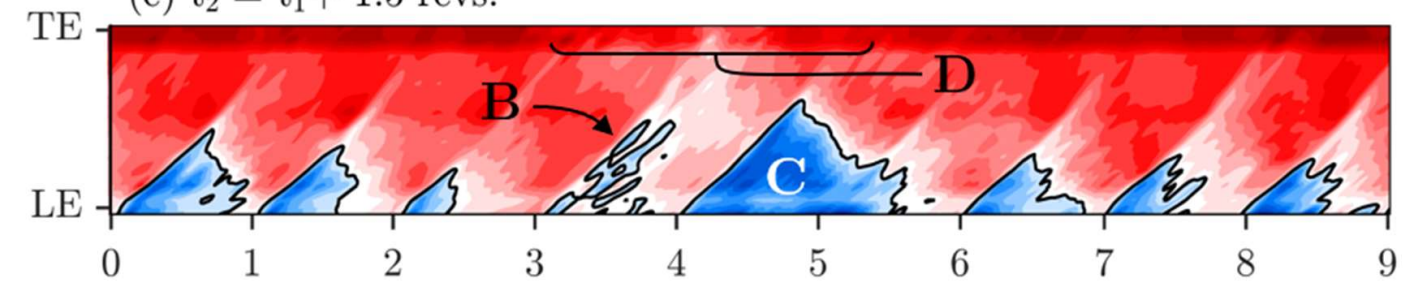

Blade passage number (-)

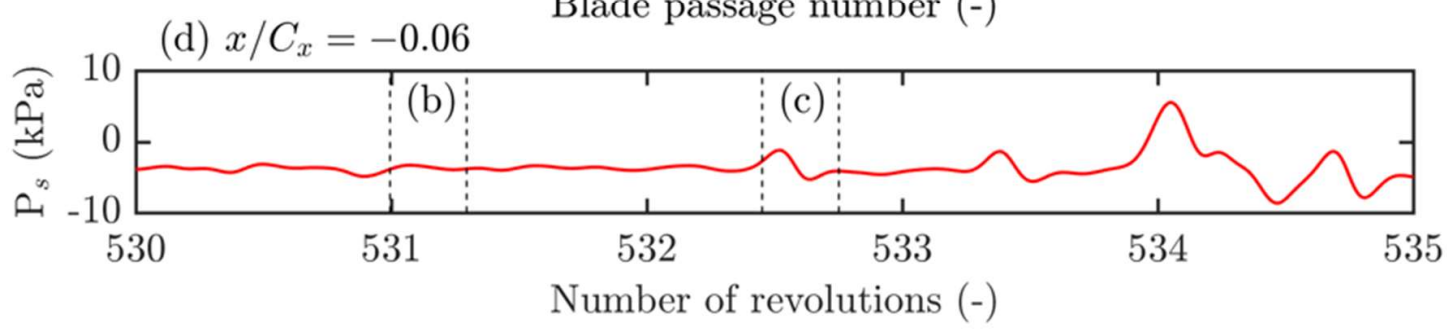

Fig. 8 Pressure contour for three operating points at $\theta=311^{\circ}$. Near nominal conditions (a), near stall conditions (bc) and associated filtered static pressure trace at leading edge few revolutions before stall (d). OPa isoline in plain black.

The last characteristic associated to the "spike" is its rotational speed. It is commonly admitted in the literature that it rotates at $70 \%$ of the rotor speed during several revolutions before triggering the rotating stall which rotates at $40 \%$ of the rotor speed. In the present case, it has been impossible 
to find a consistent mean rotational speed close to this value. Thereby, the rotational speed evolution of the first perturbation (visible on Fig. 8.(c) in our case) has been monitored in order to better describe the transition into stall. The method used to determine the speed of the perturbation, already presented in details in a previous paper (Margalida et al. 2018), consists in determining the position of the wave front of the perturbation and to derive it to obtain its speed. This method has been applied on 45 tests and to the pressure traces found in the work of Weichert and Day (2013) where the measurement configuration is equivalent to the one used here and where tip leakage flow spillage has been observed. The average speed law has then been compared to the one computed from the literature. They are both displayed on Fig. 9. In the Deverson compressor, used in the study of Weichert and Day (2013), a constant speed perturbation is indeed present during several revolutions before stall onset. However, in the present case, the speed evolution exhibits a continuous decrease from around $85 \% . \omega$, when the perturbation is first detected, to $40 \% . \omega$, when the rotating stall is established, in less than 5 rotor revolutions. The main difference between both experiments is the size of the tip gap which support its importance and its influence in the mechanism involved. Two explanations can be considered to explain this difference in behavior. On one

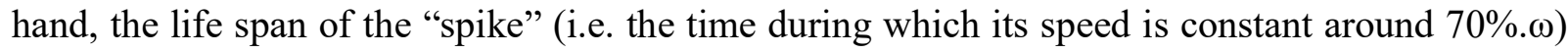
can be a function of geometrical features of the compressor, such as the tip gap size or the blade tip stagger angle, and that some configurations can promote it during several revolutions. On the other hand, the "spike" exhibited herein may be the signature of a phenomenon different from other cases where the spike is linked to tip leakage spillage, TLV breakdown or radial vortices, such as an embryonic stall cell for example that directly slows down because of its large impact on the upstream incidence,

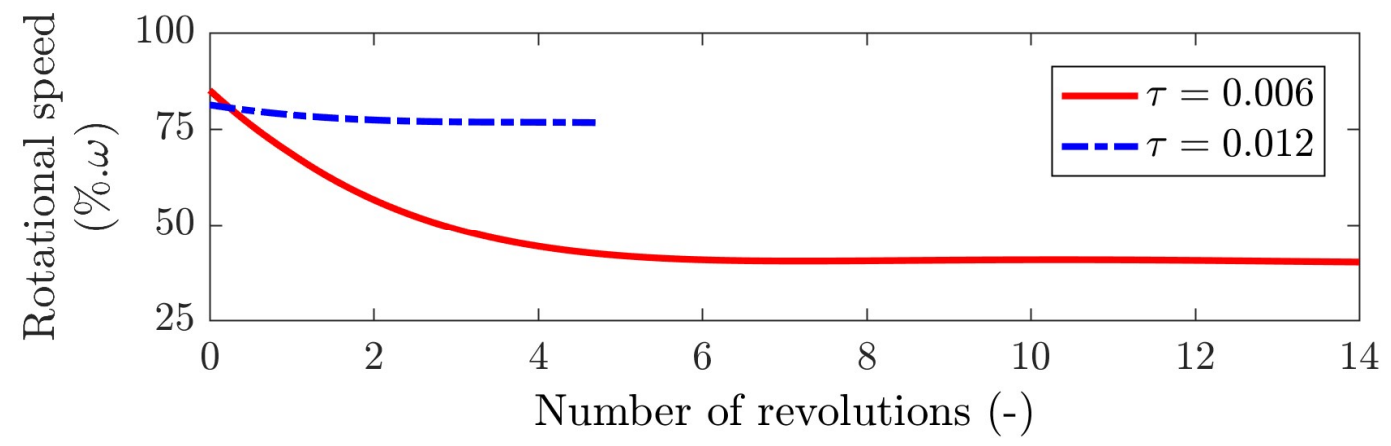

Fig. 9 First perturbation speed law in the present case (small tip gap, $\tau=0.006)$ and in the literature (Weichert and Day 2013) (medium tip gap, $\tau=0.012$ )

If we sum up everything, the rotating stall onset in the compressor used in the present study is directly preceded by a "spike" type perturbation, as historically defined, that appears suddenly and quickly slows down to the typical speed of the rotating stall. This perturbation, that occupies more than one blade pitch, at the time of its detection, is characterized by a decrease of the net work in the affected blade passage, leading to a decrease of the static pressure directly behind it. Moreover, no sign of tip leakage spillage is spotted but several revolutions before the rotating stall onset, lowpressure zones appear between the blades. These spots are most likely the trace of radial vortices, as predicted by Pullan et al. (2015) in small tip gap configurations (zero tip gap in theirs). They are 
also the evidence of leading-edge separations at the tip. As mentioned earlier, a criteria of the spike initiation has been proposed in previous papers (Deppe et al. 2005; Vo et al. 2008) but other observations doesn't fit quite well in this definition with one or more discrepancies (tip leakage vortex breakdown in addition to backflow (Yamada et al. 2012), "spike" and radial vortices in a zero tip gap geometry (Pullan et al. 2015), different mechanisms depending on the size of the tip gap leading to a "spike" (Hewkin-Smith et al. 2019)).

The evidences highlighted in this work has led to two main hypothesis when it comes to the mechanism involved in the stall formation. A schematic representation of some of these events is proposed in Fig. 10 to support the explanation. At their root, these mechanisms are similar to the one proposed by Pullan et al. (2015). An increase in incidence (Fig. 10.(a.1)) at the tip will provoke a leading edge separation and then trigger the rotating stall without spillage. However, the main difference lies in the definition of the "spike". In our case, the radial vortices (Fig. 10.(a.2)) cannot be considered as "spike", because they are not strong enough yet to induce a visible 'spike' in a single pressure signals. On the other hand, the first perturbation that could be defined as so, depicted on Fig. 10.(b.2), do not exhibit a constant speed (as seen in Fig. 9) and already provoke performance degradation, as seen in the pressure field of Fig. 8.(c) at mark "D". We can therefore wonder whether, in the present case, the first perturbation is not already an embryonic stall cell. From the previous observations, this stall cell could be initiated by one of the leading edge separations, scenario $\mathrm{S} 1$ (a.1 $\rightarrow$ b. $1 \rightarrow$ b.2), or by one of the resulting radial vortices, scenario S2 (a.1 $\rightarrow$ a.2 $\rightarrow$ b.2).

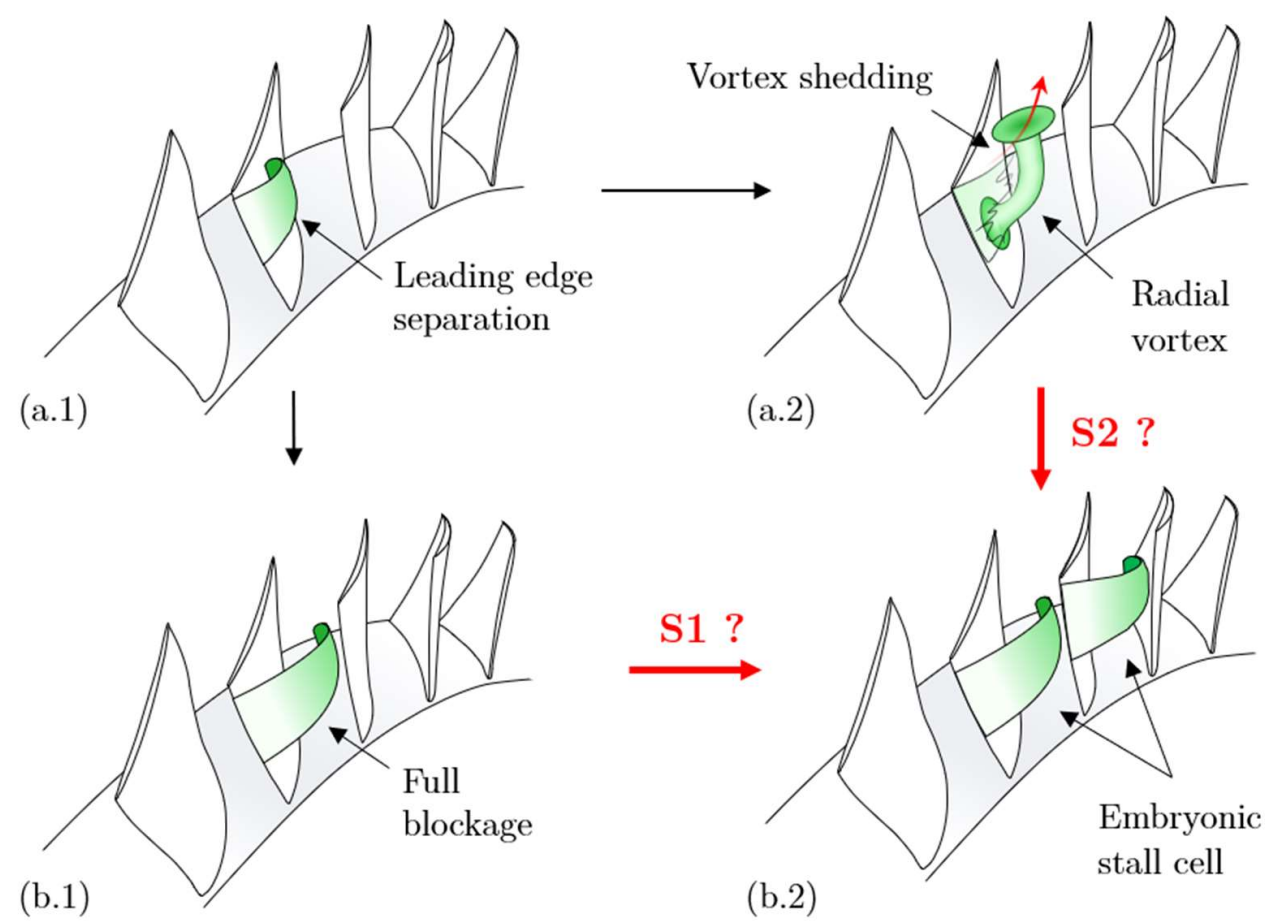

Fig. 10 Schematic representation of the proposed stall onset mechanism. (a) radial vortices formation through leading edge separation; (b) full channel blockage (large separation or bigger radial vortex) leading to embryonic stall cell formation 


\section{Active flow control effect}

The effect of the tip injection has been tested for two injection modes, continuous and pulsed. An example of the performance curves with continuous and pulsed injection compared to the baseline is given in Fig. 3. As it has already been observed, active flow control is improving the performance curve in two ways: (i) the stable operating range of the compressor is increased (decrease of the flow coefficient at stall) and, (ii) at a given flow coefficient, the pressure rise is increased. The following paragraphs aim at giving the physical explanations to this dual improvement.

To begin with, similarly to the analysis realized in the previous section, several instantaneous pressure contour maps have been compared at different operating points. The first feature that should be affected by the air injection is the tip leading edge separation and the formation of radial vortices, previously exhibited in pressure contour. To evaluate this aspect, operating points at the same flow coefficient ( $\Phi=0.37$, point A and B on Fig. 11), have been compared with and without control. A sufficiently high injected mass flow rate has been chosen to ensure noticeable effects on the flow pattern.

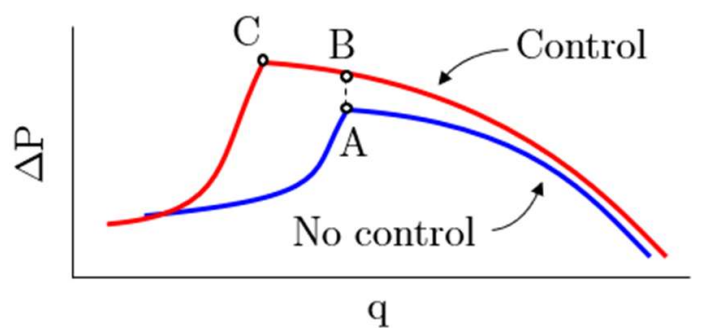

Fig. 11 Operating points compared

The instantaneous pressure contour maps for these two conditions are displayed on Fig. 12. On this figure, the signature of radial vortices is well visible on several blade passages close to the leading edge (Fig. 12.(a)) but they are totally absent when active control is activated (Fig. 12.(b)). It is also possible to see that in presence of flow control, the trace of the Tip Leakage Vortex is visible again (one of them is represented by a dotted line on Fig. 12.(b)) when it was impossible to clearly detect it without control. This observation thus confirms the stabilizing effect of tip blowing on the tip of the blade by suppressing the leading-edge separation which is at the origin of the radial vortices generation and tip leakage vortex unsteadiness. 


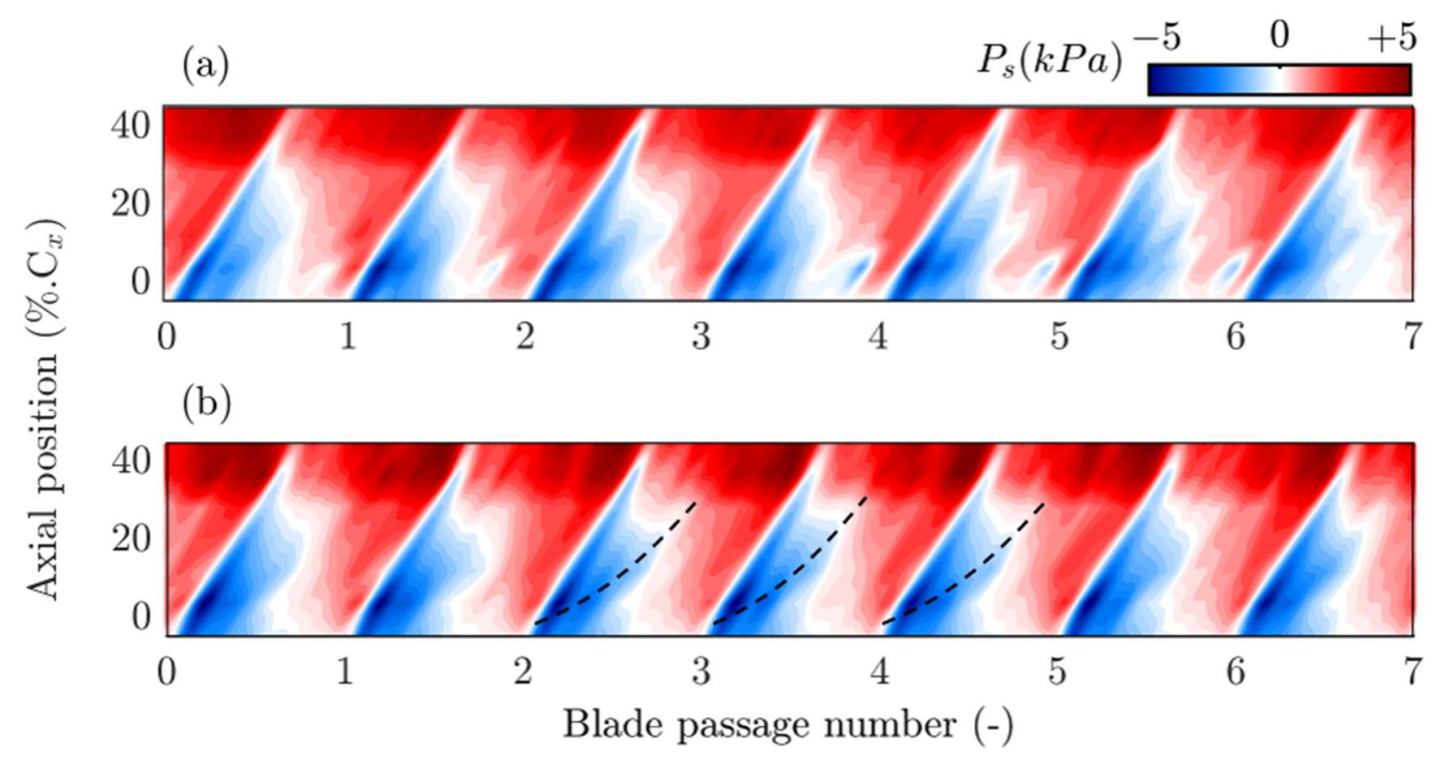

Fig. 12 Instantaneous pressure contour at the same operating point, $\Phi=0.37$, without control (a) and with control (continuous blowing, 40 injectors, $q_{i}=1.7 \% . q, v_{i}=110 \mathrm{~m} . \mathrm{s}^{-1}$ ) (b)

The effectiveness of the device is also highlighted by the comparison of the stall mechanism with and without control. For this work, instantaneous pressure contour maps near stall have been analyzed for both configurations (i.e. $\Phi=0.37$ without control and $\Phi=0.31$ with control. Points A and $\mathrm{C}$ on Fig. 11). These maps are displayed on Fig. 13, for 30 revolutions. For the sake of visibility, the blade passage frequency has been filtered. One can observe two very different behaviors from one configuration to the other. Without control we can recognize the sudden pressure rise just before stall around $t=532$ revs on Fig. 13.(a). However, several differences are visible when control is activated. High pressure spots can be seen between $x=50 \% . \mathrm{C}_{\mathrm{x}}$ and $x=60 \% . \mathrm{C}_{\mathrm{x}}$ from $t=575$ revs to $t=590$ revs when rotating stall starts. These high-pressure spots are accompanied by strong axial fluctuations of the pressure field, clearly visible through the wave pattern in the first half of the passage, and on the iso-pressure line at rotor inlet, on Fig. 13.(b). These long wavelength and small amplitude fluctuations which appear several dozens of revolutions before the onset of stall and slowly increase in strength, clearly recall mode-like perturbations (should it be in amplitude or in frequency). It should also be noted, that, in the controlled configuration, (see Fig. 3) the slope of the total-to-static performance curve, at the last stable point, is no more negative, which is a typical favorable configuration for the development of mode-like stall inception. 


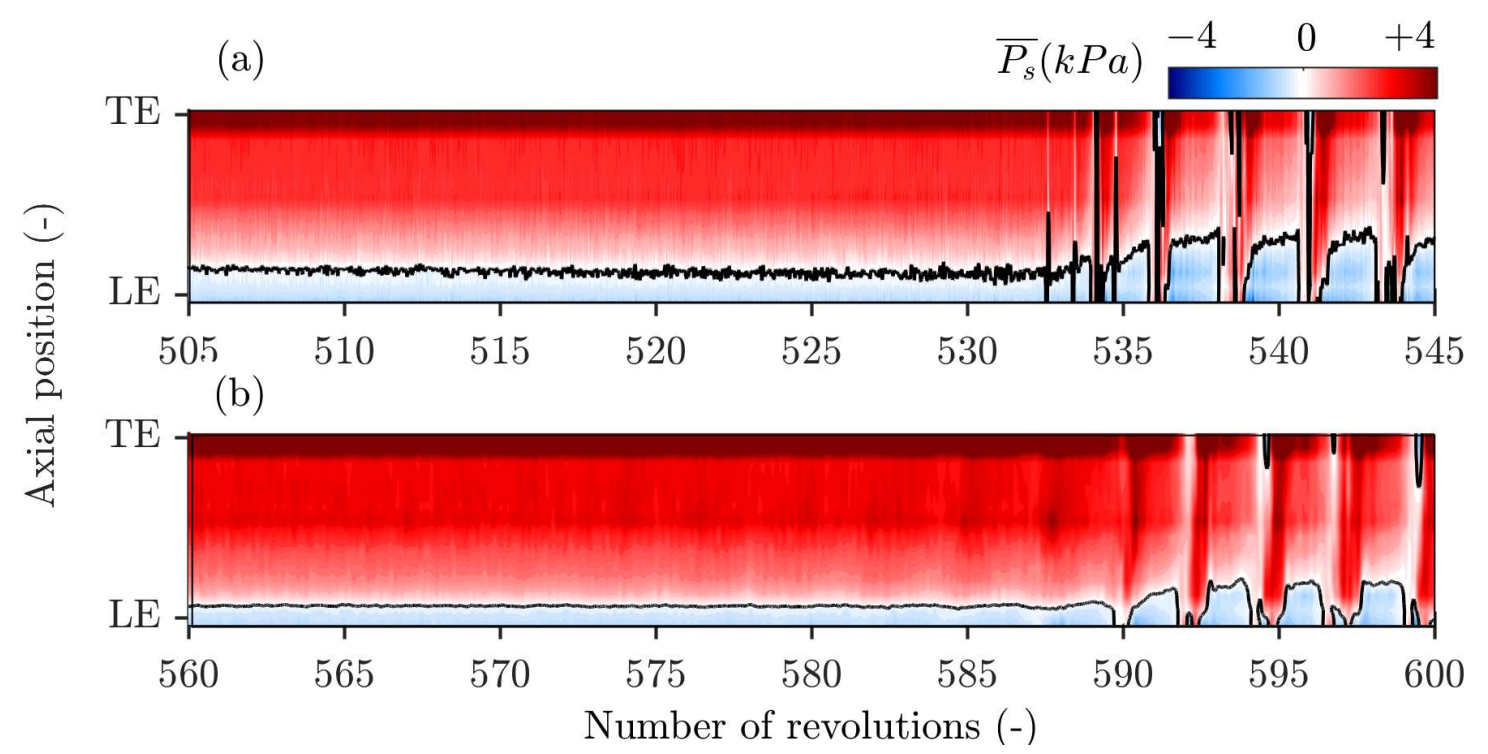

Fig. 13 Instantaneous filtered pressure contour, near stall, without control, $\Phi=0.37$, (a), and with control, $\Phi=0.31$ (continuous blowing, 40 injectors, $q_{i}=1.7 \% . q, v_{i}=110 \mathrm{~m}^{-1} \mathrm{~s}^{-1}$ ) (b). 0 Pa isoline in plain black

To evaluate how the air injection affects the stability of the compressor and thus the position of the stability limit, an extensive parametric study of the injection has been realized. Several parameters have been studied and two main cases are particularly interesting for this matter: the effect of the arrangement and the effect of the pulse width, or more precisely, the duration without blowing, called $t_{\text {off, }}$ which is changed through the duty cycle of the solenoid valve. To study specifically the effect of the $t_{\text {off }}$, the duty cycle and the frequency of the injection have been setup to ensure that (i) the frequency has no effect on the performances and (ii) the $t_{\text {off }}$ is significantly smaller than the total time of one injection cycle. This type of injection, schematized in Fig. 14, is referred as pseudo-continuous blowing. The investigated ranges of $t_{\text {off }}$ and their corresponding frequency are summarized in Fig. 14.

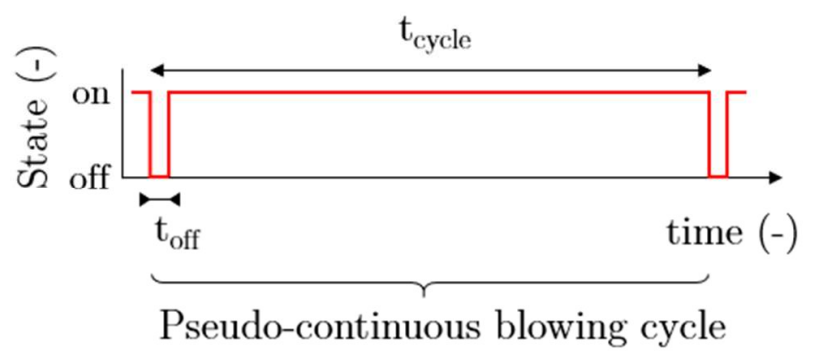

\begin{tabular}{ccc}
\hline $\mathbf{t}_{\text {off }}$ and blowing frequency couples \\
\hline \multicolumn{1}{c}{$\mathrm{t}_{\text {off }}(-)$} & $\mathrm{f}(\mathrm{Hz})$ & $\mathrm{t}_{\text {cycle }}(-)$ \\
$1 \rightarrow 16$ pitchs & $17,8 \mathrm{~Hz}$ & 3 revs. \\
$1 \rightarrow 20$ revs. & $1 \mathrm{~Hz}$ & 53 revs. \\
$20 \rightarrow 40$ revs. & $0,5 \mathrm{~Hz}$ & 106 revs. \\
\hline
\end{tabular}

Fig. 14 Schematic representation of a blowing cycle

The effect of the $t_{\text {off }}$ is firstly examined through Fig. 15.(b) where the Stall Margin Improvement (SMI) is plotted as a function of the duration without blowing. Four performance curves, with and without control, are also displayed on Fig. 15.(a). When the duration off-injection is changed, the compressor experiences two decoupled effects. To account that, the SMI has been decomposed 
into its two components, the flow coefficient decrease, $\Delta \Phi=100 \times \frac{\left(\Phi_{\mathrm{B}}-\Phi_{\mathrm{C}}\right)}{\Phi_{\mathrm{B}}}$, and the pressure rise coefficient increase $\Delta \Psi_{t-s}=100 \times \frac{\left(\Psi_{C}-\Psi_{B}\right)}{\Psi_{B}}$, with subscript $\mathbf{B}$ for the baseline without control and subscript $\mathbf{C}$ for the control case.
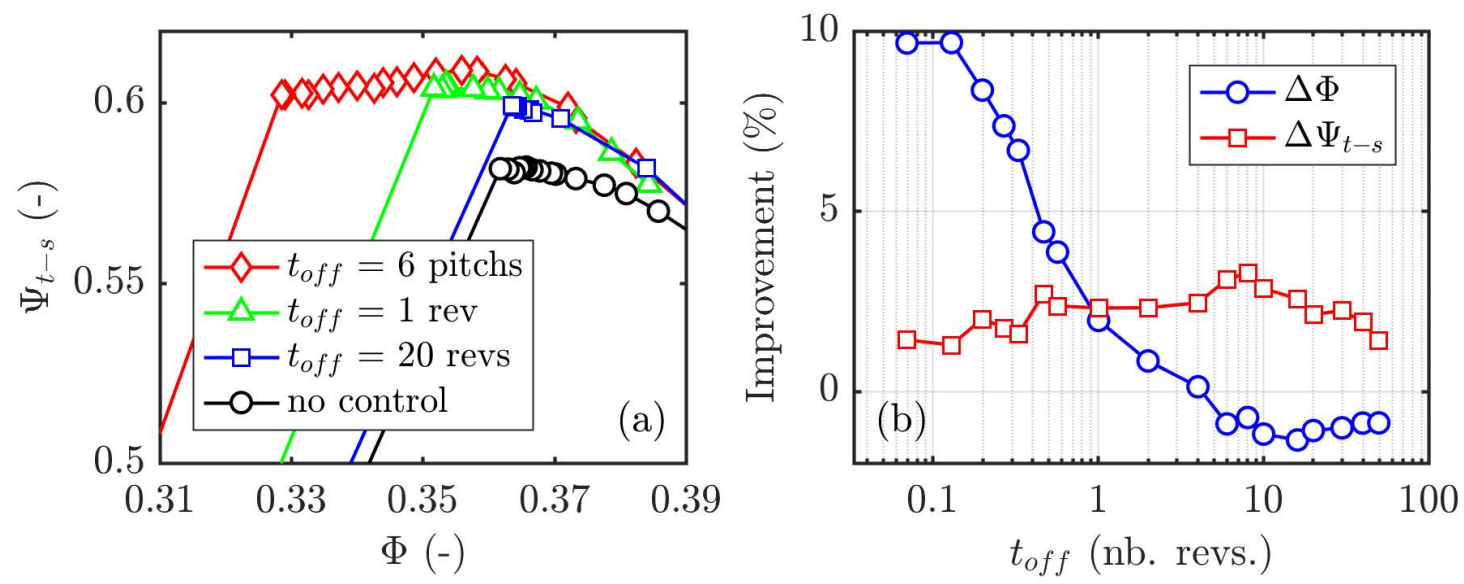

Fig. 15 Effect of the duration without control on the stability and performances of the compressor (pseudo-continuous blowing, 40 injectors, $q_{i}=0.75 \% . q, v_{i}=60 m . s^{-1}$ )

The first improvements of the stalling mass flow rate are obtained when the duration without blowing becomes smaller than the order of magnitude of few rotor revolutions. Indeed, as depicted on Fig. 15.(b), under 3-4 revolutions, the mass flow rate at stall starts decreasing quickly and continuously. A plateau is then reached when this duration gets close to the order of magnitude of few blade passages. This behavior can be linked to the mechanism presented earlier, involving the formation of radial vortices. When the $t_{\text {off }}$ duration is small enough, these structures have less time to develop ${ }^{2}$. For very small $t_{\text {off }}$, radial vortices, and leading-edge separations, are totally suppressed by the blowing and decreasing it does not bring more benefits, thus explaining the plateau. That is also why reducing the off-blowing duration from one revolution to one blade pitch only affect the mass flow rate at stall. The same results are obtained when the angular space between each injector is changed. Decreasing this distance, allows to decrease the mass flow rate at stall.

The second effect visible concerns the pressure rise improvement. While the improvement on the mass flow rate suddenly disappears for larger $t_{\text {off }}$ values, a noticeable gain in pressure rise remains, even for extended period without blowing. In the present case, for duration ranging from 10 to 50 rotor revolutions, this gain slowly disappears but it is still visible for the longer periods... As showed by Suder et al. (2001), and as pointed out above, this improvement is obtained through the decrease of the blade loading at the tip of the blades and its redistribution along the span. It appears,

\footnotetext{
${ }^{2}$ It can be noted here that for long $t_{\text {off, }}$, the improvement on the mass flow rate becomes negative. In those situations, rotating stall onset most likely appears during the period without blowing because of the radial vortices. During this period, the apparent flow coefficient is the same than without blowing. However, each points of the curve are averaged over one injection cycle. The displayed flow coefficient is thus a combination of the main and injected mass flow rate. The flow coefficient at stall thus appears greater and that is why the SMIq is negative.
} 
through our results, that this improvement, unlike the effect on the mass flow rate, is persistent and can be obtained with small and sparse impulses.

Thus, in summary, increasing the axial velocity at tip through air blowing (i) prevents the occurrence of the separations on the suction side, (ii) decreases the blade loading at tip. This leads to a stabilization of the TLV and probably also to a decrease of its magnitude.

These two effects prevent completely the development of the flow mechanism at the origin of the spike-type instability described in the first part of the paper. The operating range of the compressor is thus extended until it reaches an area where the slope of the characteristic curve is becoming slightly positive, which leads to a mode-like stall inception. The mode perturbation become possible when the critical incidence at the tip isn't reached before the maximum of the performance curve (Camp and Day 1997). Thus, using active flow control at the tip allows to avoid spike type rotating stall but does not immunize from mode perturbation that can therefor still grow. Secondly, the secondary flows at tip, and the losses associated with them, are strongly reduced which explains the increase of the pressure rise.

\section{CONCLUSION}

In this paper, the flow mechanisms involved during the stall inception with and without active flow control have been analyzed.

Without control, the axial compressor used in this study exhibits identical characteristics than "spike" type rotating stall, such as the negative slope of the total-to-static performance curve at stall or the absence of modal activities.

However, despite apparent similarities with "spike" mechanisms, some differences emerge from the present results compared to previous experimental studies but seem to confirm observations from numerical works for small tip clearance geometries.

While no sign of backflow or tip leakage spillage has been observed, several low-pressure spots are present several dozens of revolutions before stall onset. These spots are most likely the signature of radial vortices formed by leading edge separations at the tip of the blade, as described by Pullan et al. (2015), with one end attached to the suction side and the other end to the casing.

Moreover, it has been shown that the first perturbation detected, classically called "spike", doesn't rotate at a fixed rotational speed of 70\%. $\omega$ but instead quickly and continuously slows down from $85 \%$ to $40 \%$. $\omega$. This perturbation occupies more than one blade pitch and is followed, downstream, by a drop of the static pressure suggesting that this perturbation is already an embryonic stall cell.

This paper has then investigated the effect of active flow control on the mechanisms involved at stall. The control system has successfully increased the operating range of the compressor by counteracting "spike" mechanisms and by moving the last stability point close to the maximum of the performance curve, where "mode" type rotating stalls can occur. Indeed, radial vortices totally disappear when blowing is used and modal oscillations are spotted before the onset of rotating stall. An emphasize can be made on this last observation because it also suggests that the SMI granted 
by any active flow control system, designed to act on the spike mechanisms, will always be limited by the maximum of the performance curve.

The active control system enables a dual improvement by decreasing the stalling mass flow rate and increasing the pressure rise for a given operating point. The first effect is obtained by the suppression of the leading-edge separations at the tip, highlighted by the disappearance of radial vortices, and the second by a reduction of the losses associated to the secondary flows and the instability of the Tip Leakage Vortex.

A particular emphasize has also been carried out on the different characteristic times of these two effects. On one hand, to suppress correctly and permanently leading-edge separations, the duration between two encounters of a jet by a given blade need to be small enough (1-2 blade passages in our case). This will constraint the minimum frequency for pulsed injection and the number of injectors to be used which will also depend on the rotational speed of the rotor. On the other hand, the pressure rise improvement, obtained by redistribution of the blade loading, appears to last longer (around 50 revolutions in our case).

\section{LIST OF SYMBOLS}

$\begin{array}{ll}\mathrm{X}_{\mathrm{t}-\mathrm{s}} & \text { Total-to-static quantity } \\ \Delta \mathrm{P} & \text { Pressure rise }(\mathrm{Pa}) \\ \Psi & \text { Pressure rise coefficient, } \Psi_{\mathrm{t}-\mathrm{s}}=\Delta \mathrm{P}_{\mathrm{t}-\mathrm{s}} / 0.5 \rho \mathrm{U}_{\mathrm{tip}}{ }^{2} . \\ \mathrm{q} & \text { Mass flow rate }\left(\mathrm{kg} \cdot \mathrm{s}^{-1}\right) \\ \Phi & \text { Flow coefficient, } \Phi=\mathrm{V}_{\mathrm{x}} / \mathrm{U}_{\text {tip }} \\ \mathrm{P}_{\mathrm{s}} & \text { Static pressure }(\mathrm{Pa}) \\ \mathrm{P}_{\mathrm{t}} & \text { Total pressure }(\mathrm{Pa}) \\ \overline{\mathrm{Ps}} & \text { Filtered static pressure }(\mathrm{Pa}) \\ \mathrm{u}_{\mathrm{x}} & \text { Axial direction } \\ \mathrm{u}_{\mathrm{r}} & \text { Radial direction } \\ \mathrm{u}_{\theta} & \text { Tangential direction } \\ \omega & \text { Rotor rotational speed }(\mathrm{rpm}) \\ \mathrm{U}_{\mathrm{mid}} & \text { Rotor speed at mid high }\left(\mathrm{m} . \mathrm{s}^{-1}\right) \\ \mathrm{U}_{\text {tip }} & \text { Rotor speed at tip }\left(\mathrm{m} . \mathrm{s}^{-1}\right) \\ \mathrm{V}_{\mathrm{x}} & \text { Absolute axial velocity }\left(\mathrm{m} . \mathrm{s}^{-1}\right) \\ \rho & \left.\text { Air density (kg.s } \mathrm{s}^{-1}\right) \\ \mathrm{C} & \text { Blade chord (mm) } \\ \mathrm{C}_{\mathrm{x}} & \text { Blade axial chord (mm) } \\ \mathrm{s} & \text { Tip clearance size }(\mathrm{mm}) \\ \tau & \text { Normalized tip clearance size, } \mathrm{s} / \mathrm{C} \mathrm{(-)} \\ \mathrm{TLV} & \text { Tip Leakage Vortex } \\ \mathrm{TLF} & \text { Tip Leakage Flow } \\ & \end{array}$




$\begin{array}{ll}\mathrm{x} & \text { Axial position }(\mathrm{mm}) \\ \mathrm{t} & \text { Time } \\ \theta & \text { Angular position }\left(^{\circ}\right) \\ \mathrm{LE} & \text { Leading edge } \\ \mathrm{TE} & \text { Trailing edge } \\ \mathrm{t}_{\mathrm{off}} & \text { Duration without blowing }(\mathrm{s}) \\ \mathrm{t}_{\mathrm{cycle}} & \text { Duration of one } \\ \mathrm{q}_{\mathrm{i}} & \text { Injected mass flow rate }\left(\mathrm{kg} . \mathrm{s}^{-1}\right) \\ \mathrm{V}_{\mathrm{i}} & \text { Injection velocity }\left(\mathrm{m} \cdot \mathrm{s}^{-1}\right) \\ \mathrm{SMI} & \text { Stall Margin Improvement } \\ \Delta \Phi & \text { Flow coefficient decrease }(\%) \\ \Delta \Psi_{\mathrm{t}-\mathrm{s}} & \text { Pressure rise coefficient increase }(\%)\end{array}$

\section{REFERENCES}

Camp TR, Day IJ (1997) A Study of Spike and Modal Stall Phenomena in a Low-Speed Axial Compressor. In: Volume 1: Aircraft Engine; Marine; Turbomachinery; Microturbines and Small Turbomachinery. ASME, p V001T03A109

Cumpsty NA (1989) Part-Circumference Casing Treatment and the Effect on Compressor Stall. In: ASME 1989 International Gas Turbine and Aeroengine Congress

Day IJ (1993) Stall Inception in Axial Flow Compressors. J Turbomach 115:1. https://doi.org/10.1115/1.2929209

Deppe A, Saathoff H, Stark U (2005) Spike-Type Stall Inception in Axial-Flow Compressors

Fujita H, Takata H (1984) A Study on Configurations of Casing Treatment for Axial Flow Compressors. Bull JSME 27:1675-1681

Hewkin-Smith M, Pullan G, Grimshaw SD, et al (2019) The Role of Tip Leakage Flow in SpikeType Rotating Stall Inception. J Turbomach 141:061010. https://doi.org/10.1115/1.4042250

Hoying DA, Tan CS, Vo HD, Greitzer EM (1999) Role of Blade Passage Flow Structurs in Axial Compressor Rotating Stall Inception. J Turbomach 121:735. https://doi.org/10.1115/1.2836727

Inoue M, Kuroumaru M, Tanino T, et al (2001) Comparative Studies on Short and Long LengthScale Stall Cell Propagating in an Axial Compressor Rotor. J Turbomach 123:24. https://doi.org/10.1115/1.1326085

Inoue M, Kuroumaru M, Yoshida S, et al (2004) Effect of Tip Clearance on Stall Evolution Process in a Low-Speed Axial Compressor Stage. In: Volume 5: Turbo Expo 2004, Parts A and B. ASME, pp 385-394

Kefalakis M, Papailiou KD (2007) Detailed Measurements on an Axial Compressor Stage with Application of Discrete Tip Injection for Increasing the Surge Margin. In: Volume 6: Turbomachinery, Parts A and B. ASME, pp 101-111 
Li J, Lin F, Tong Z, et al (2014) The Dual Mechanisms and Implementations of Stability Enhancement With Discrete Tip Injection in Axial Flow Compressors. J Turbomach 137:031010. https://doi.org/10.1115/1.4028299

Margalida G, Dazin A, Joseph P, Roussette O (2018) Detailed Pressure Measurements During the Transition to Rotating Stall in an Axial Compressor: Influence of the Throttling Process. In: ASME 2018 5th Joint US-European Fluids Engineering Division Summer Meeting. American Society of Mechanical Engineers, p V001T01A001

Margalida G, Joseph P, Roussette O, Dazin A (2020) Comparison and Sensibility Analysis of Warning Parameters for Rotating Stall Detection in an Axial Compressor. Int $\mathbf{J}$ Turbomachinery, Propuls Power 5:16. https://doi.org/10.3390/ijtpp5030016

McDougall NM, Cumpsty NA, Hynes TP (1990) Stall Inception in Axial Compressors. J Turbomach 112:116. https://doi.org/10.1115/1.2927406

Nie C, Xu G, Cheng X, Chen J (2002) Micro Air Injection and Its Unsteady Response in a LowSpeed Axial Compressor. J Turbomach 124:572. https://doi.org/10.1115/1.1508383

Pullan G, Young AM, Day IJ, et al (2015) Origins and Structure of Spike-Type Rotating Stall. J Turbomach 137:051007. https://doi.org/10.1115/1.4028494

Smith GDJ, Cumpsty NA (1983) Flow Phenomena in Compressor Casing Treatment. J Eng Power $106: 532-541$

Stößel M, Bindl S, Niehuis R (2013) Rotating Stall Inception Inside the Low Pressure Compressor of a Twin-Spool Turbofan Engine. In: Volume 6A: Turbomachinery. American Society of Mechanical Engineers

Stößel M, Bindl S, Niehuis R (2014) Ejector Tip Injection for Active Compressor Stabilization. In: Volume 2A: Turbomachinery. American Society of Mechanical Engineers

Strazisar AJ, Bright MM, Thorp S, et al (2004) Compressor Stall Control Through Endwall Recirculation. In: Volume 5: Turbo Expo 2004, Parts A and B. ASME, pp 655-667

Suder KL, Hathaway MD, Thorp SA, et al (2001) Compressor Stability Enhancement Using Discrete Tip Injection. J Turbomach 123:14. https://doi.org/10.1115/1.1330272

Takata H, Tsukuda Y (1977) Stall Margin Improvement by Casing Treatment-Its Mechanism and Effectiveness. J Eng Power 99:121-133

Veglio M, Dazin A, Bois G, Roussette O (2014) Pressure Measurements in an Axial Compressor: from Design Operating Conditions to Rotating Stall Inception. In: 49th Symposium of Applied Aerodynamics

Vo HD, Tan CS, Greitzer EM (2008) Criteria for Spike Initiated Rotating Stall. J Turbomach 130:011023. https://doi.org/10.1115/1.2750674

Weichert S, Day I (2013) Detailed Measurements of Spike Formation in an Axial Compressor. J Turbomach 136:051006. https://doi.org/10.1115/1.4025166

Yamada K, Kikuta H, Furukawa M, et al (2013) Effects of Tip Clearance on the Stall Inception Process in an Axial Compressor Rotor. In: Volume 6C: Turbomachinery. ASME, $p$ V06CT42A035 
Yamada K, Kikuta H, Iwakiri K, et al (2012) An Explanation for Flow Features of Spike-Type Stall Inception in an Axial Compressor Rotor. J Turbomach 135:021023. https://doi.org/10.1115/1.4007570

Young AM, Day IJ, Pullan G (2012) Stall Warning by Blade Pressure Signature Analysis. J Turbomach 135:011033. https://doi.org/10.1115/1.4006426 